\title{
In Vivo Mechanical Properties of the Developing Airway
}

\author{
THOMAS H. SHAFFER, VINOD K. BHUTANI, MARLA R. WOLFSON, RAYMOND B. PENN, \\ AND NGHIA N. TRAN \\ Departments of Physiology and Pediatrics [T.H.S., M.R.W., R.B.P.], Temple University School of Medicine, \\ Philadelphia, Pennsylvania 19140, Section of Newborn Pediatrics [V.K.B], Pennsylvania Hospital, Philadelphia, \\ Pennsylvania 19107; and Rolling Hills Hospital [N.N.T.], Philadelphia, Pennsylvania 19117
}

\begin{abstract}
The inherent mechanical characteristics of the airways are determined in part by their elastic and viscoelastic properties. As compliant structures during early development, the airways are susceptible to significant distention and collapse, depending on the proportionality between airway volume and transmural pressure. To characterize the age-related changes in airway mechanical properties, the elastic and viscoelastic behavior of in vivo tracheal segments were evaluated in preterm and newborn lambs over a wide range of developmental age (108 to 154 days postconceptional age). Tracheal pressure-vol relationships and concomitant airway compliance measurements were used to determine elastic behavior. Calculations of the tracheal relaxation time constant on the same tracheal segments were used to evaluate airway viscoelastic behavior. Data demonstrated a significant $(p<0.01)$ correlation with developmental age. With increasing age, the airways were found to be less compliant, and the tracheal relaxation time constant was observed to decrease. The difference in elastic properties of the trachea, in vivo compared to in vitro, suggest that neural-humoral and surrounding connective tissue factors may affect the elasticity of the developing airway. Although the modulating effects of smooth muscle tone and supporting connective tissue assist in the control of airway dimension and resistance to airflow in the intact airway, the age-related differences in the elastic properties may be a factor that predisposes the more immature airway to positive pressure-induced damage. $(\mathrm{Pe}$ diatr Res 25:143-146, 1989)
\end{abstract}

\section{Abbreviations}

$V$, initial tracheal segment volume

$\mathrm{T}_{\mathrm{R}}$, smooth muscle relaxation time constant

$P_{0}$, pressure at time 0

$P_{s s}$, pressure at steady state conditions.

$\mathrm{C}_{s}$, segmental airway compliance

Immature airways have been shown to be particularly susceptible to damage associated with the vigorous ventilatory support often required in the management of premature infants $(1,2)$. Recent clinical and experimental investigations have implicated the mechanical properties of immature airways in the pathogenesis of acquired tracheomegaly and bronchopulmonary dysplasia as well as complications secondary to airway damage such as

Received February 2, 1988; accepted September 20, 1988

Correspondence Thomas H. Shaffer, Ph.D. Department of Physiology, Temple University School of Medicine, Philadelphia, PA 19140.

Supported in part by NIH Grants NHLBI HL 30525 and NHLBI HL 32031. increased dead space and gas trapping (3-6). These findings underscore the need for determining the functional characteristics of immature airways.

Numerous investigators have characterized the elastic and viscoelastic properties of the airways by using a variety of experimental techniques, in a number of species, and at different stages of development (5-13). To date, only one study, using in vitro rabbit tracheae, has examined airway mechanical properties throughout a range of early development according to a consistent protocol and experimental technique (5). Although this study has provided valuable information concerning age-related differences in airway mechanics, it is difficult to extrapolate these data to the fully innervated and perfused in vivo trachea. Furthermore, the in vitro preparation cannot address the influence of neuralhumoral and supporting structures on the in situ trachea, which may also be age-related.

The in vivo study of airway physiology in the premature animal has been limited by the inability to maintain physiologic gas exchange and acid-base status that potentially could influence airway properties (14). Recent advances in liquid ventilation techniques have enabled us to establish a stable and viable preterm animal preparation to study physiologic development beginning at the early stages of gestation (15). Using this technology, we evaluated airway compliance and the relaxation time constant of in vivo tracheal segments in lambs to characterize age-related changes in elastic and viscoelastic properties of the developing airway. Smooth muscle tone and the influence of connective tissue are suggested as possible determinants of differences in tracheal mechanics observed with respect to age and the in vivo versus in vitro condition.

\section{MATERIALS AND METHODS}

Animal preparation. Fifteen preterm lambs (108 to 137 days postconceptional age; term $=147$ days) and seven newborn lambs (148 to 154 days postconceptional age) were studied. In the preterm lamb preparation, the dated ewes were restrained in a prone position after an intramuscular injection of ketamine $\mathrm{HCl}(5 \mathrm{mg} / \mathrm{kg})$. Epidural anesthesia $(0.5-1.0 \mathrm{mg} / \mathrm{kg}$ of $0.75 \%$ bupivicaine $\mathrm{HCl}$ ) was then induced, and the uteus was exposed. Through a uterotomy, the head of the preterm lamb was allowed to emerge; inspiration was prevented by placing a rubber glove filled with warm $\left(37-39^{\circ} \mathrm{C}\right)$ saline over the head. After a local infiltration of $1 \%$ lidocaine in the neck, the right carotid artery and the right jugular vein were each cannulated with appropriate sized French 5 or 8 polyvinyl catheters. A tracheotomy was performed on the distal trachea, which was cannulated for ventilation. The proximal segment was then cannulated with an appropriate sized catheter through an incision in the cricothyroid membrane. As shown in Figure 1, a catheter was also inserted in the most caudal end of the bypassed segment. 


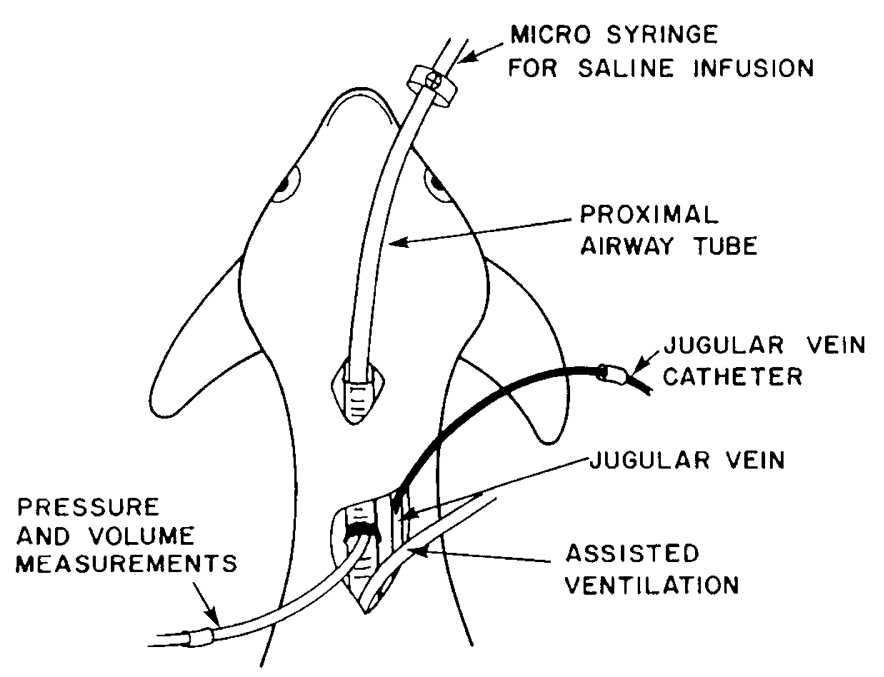

Fig. 1. Schematic of the bypassed segment of the cervical trachea.

A bolus of $50 \%$ sodium bicarbonate solution $(2.5 \mathrm{ml} / \mathrm{kg})$, ketamine $\mathrm{HCl}(5 \mathrm{mg} / \mathrm{kg})$, and a subsequent bolus of pancuronium bromide $(0.1 \mathrm{mg} / \mathrm{kg})$ were administered intravenously. The animal was removed from the uterus, the rubber glove was removed from the head and the umbilical cord was clamped and tied. The animal was immediately connected to the liquid ventilating system.

The animal was dried and warmed under a radiant heat source. An intravenous crystalloid infusion $(10 \%$ dextrose with $10 \mathrm{mEq}$ sodium bicarbonate/ $100 \mathrm{ml}$ fluid) was commenced at a rate of $3 \mathrm{ml} \cdot \mathrm{kg}^{-1} \cdot \mathrm{h}^{-1}$; ECG leads were positioned; and the catheters were connected to appropriate pressure transducers. Data were recorded on a Grass polygraph (model 7) (Grass Instrument Co., Quincy, MA) throughout the study period while the preterm lambs remained on the liquid ventilating system.

The newborn lambs were anesthetized $(30 \mathrm{mg} / \mathrm{kg}$ intraperitoneal sodium pentabarbital) and secured in the supine position. Catheter placement, surgical preparation of the tracheal segment, and cardiovascular data recording were identical to that used for the preterm lamb.

Ventilation procedure. To maintain the biologic stability of the in vivo airway preparation, all preterm lambs were ventilated with oxygenated fluorocarbon liquid via the distal tracheal cannula. Liquid ventilation with fluorocarbon (RIMAR 101) was achieved using a previously described and modified liquidbreathing system (15). Briefly, the liquid ventilation system acted as a vol ventilator in which the tidal vol, frequency, I:E ratio, and liquid flow could be adjusted. Oxygenation of the liquid and removal of carbon dioxide from the liquid was accomplished with a membrane oxygenator (Scientific Medical Life Systems, Inc., model 3500; Scientific Medical Life Systems Inc., Minneapolis, MN). The temperature of the liquid was maintained at $39^{\circ} \mathrm{C}$ using an electrically controlled temperature regulator and heater (Masterline Bath and Circulator, model 2095, Marietta, $\mathrm{OHIO}$ ). The $\mathrm{PO}_{2}$ and the $\mathrm{PCO}_{2}$ of the liquid were sampled from the system before and during liquid ventilation of the animal. Oxygenated liquid was removed from the liquid-breathing system and placed in a suspended reservoir. A vol equivalent to the estimated functional residual capacity $(30 \mathrm{ml} / \mathrm{kg})$ of the lungs was instilled from this reservoir via the tracheotomy tube into the animal's lungs. Postural and thoracic manipulations were performed to equilibrate the fluorocarbon with prenatal lung fluid.

Tidal vol was measured by the change in the animal's wt using a previously described strain gauge platform (15). This method also served to monitor the functional residual capacity and was accurate to within $1 \mathrm{ml}$ of fluorocarbon liquid. Based on previous experiments, ventilation schemes were adjusted for effective carbon dioxide elimination and maintenance of physiologic arterial carbon dioxide tensions. Animals were ventilated at a mean tidal vol of approximately $12-16 \mathrm{ml} / \mathrm{kg}$, and frequency of four to six breaths/min.

Newborn lambs were allowed to breathe spontaneously through the distal trachea cannula. The cardiopulmonary stability of both newborn and preterm lambs were confined with arterial blood gas tensions, $\mathrm{pH}$, blood pressure, and ECG measurements. The vascular and neural integrity of the bypassed tracheal segment was confirmed by pharmacologic stimulation at the end of each experiment.

Pressure-vol relationships. The distal end of the bypassed tracheal segment (Fig. 1) was connected to a micropipette system and pressure transducer (Statham P23db; Hato Rey, PR). The transducer signal was monitored and recorded on the Grass polygraph. A 2-way valve was used to open and close the tubing circuit to the micropipette (calibrated $5 \times 0.1 \mathrm{ml}$ ). An injection system (Hamilton microsyringe and injector, Hamilton Industries, Two Rivers, WI) was attached to the proximal segment catheter and used for infusion and withdrawal. The bypassed tracheal segment was flushed with normal saline to clear away mucus or blood. The saline solution was colored with Cariogreen (indocyanine green; Hynson, Westcott, and Dunning, Inc., Baltimore, MD) for easier visual reading in the micropipette system and to detect leaks in the system. The micropipette was mounted horizontally at the same plane as the segment, and care was taken to minimize hydrostatic pressure effects.

The bypassed tracheal segment was initially opened to ambient pressure under control conditions. This allowed equilibration of pressures such that the transmural pressure across the wall of the trachea was at a baseline of 0 . The system was then closed to atmosphere. Using the Hamilton injection system, predetermined aliquots of $0.1-0.2 \mathrm{ml}$ were introduced into the closed tracheal system at 15 -s intervals, until an intratracheal pressure (60 $\mathrm{cm} \mathrm{H} \mathrm{H}_{2} \mathrm{O}$ for preterms or $80 \mathrm{~cm} \mathrm{H}_{2} \mathrm{O}$ for newborns) was produced, and then removed over the same time period (16). Pressure changes concurrent with the step-vol introduction and withdrawal were monitored. Figure 2 illustrates the resulting pressure changes due to the step-vol. When a step-vol was added to the resting isolated tracheal segment, there was a concurrent rise in pressure. This pressure response typically peaked and then decreased to a stable plateau.

The tracheal segment was assumed to be a cylindrical configuration (8). The segmental length was determined as the distance between the proximal and distal ligatures. Although segmental lengths among animals varied to a small degree due to age-

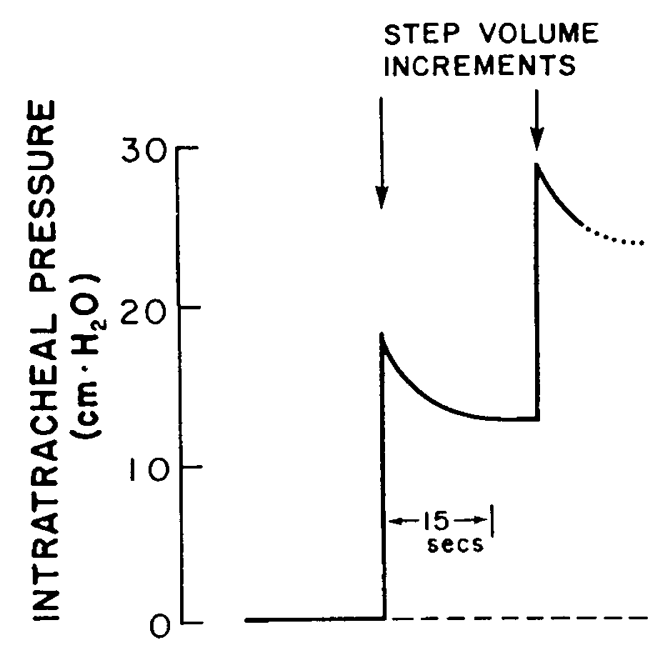

TIME

Fig. 2. Resultant pressure changes in the bypassed tracheal segment due to step-vol injection of normal saline. 
related differences in in situ length, tracheal length to radius ratios were similar among all animals and were sufficiently high (always more than nine) to minimize the effect cannulation may have had on pressure-vol characteristics. As previously described (8), the diameter was measured directly with a micrometer and indirectly by measuring the circumference of the section. These data were then used to calculate mathematically the V.

Vol changes, expressed as a percentage of resting segment vol, and corresponding pressures were determined and plotted to provide individual quasistatic pressure-vol relationships (8). Specific airway compliance values were determined as the relative changes in resting vol over a pressure range of $0-10 \mathrm{~cm} \mathrm{H}_{2} \mathrm{O}$ on the deflation limb of the pressure-vol curves. This pressure range represents the linear portion of the deflation curve for all groups. Based on regression analysis, the exponential pressure decay after an incremental step-vol to the tracheal segment (Fig. 2) was described as:

$$
\mathrm{P}=\mathrm{P}_{\mathrm{ss}}+\left(\mathrm{P}_{\mathrm{o}}-\mathrm{P}_{\mathrm{ss}}\right) \mathrm{e}^{-\mathrm{t} / \tau} R \cdots \cdots
$$

where $\mathrm{P}=$ pressure at any given time $(\mathrm{t}), \mathrm{P}_{\mathrm{o}}$ is the pressure attime 0 (experimentally extrapolated), $\mathrm{P}_{\mathrm{ss}}$ is the pressure at steady state conditions, and $\tau_{R}$ is the smooth muscle relaxation time constant.

Two types of statistical analyses were used in this study. Newborn and preterm data were compared for significance using the ANOVA. To further study the interrelationships between various experimental parameters, linear regression analyses were performed.

\section{RESULTS}

Both the spontaneously breathing newborn lambs and the liquid ventilated preterm lambs proved to be a relatively stable experimental model for the study of in vivo airway function. Preterm lambs supported by fluorocarbon liquid ventilation were biologically stable as determined by gas exchange and acid-base data $\left(\mathrm{PO}_{2}\right)>100 \mathrm{~mm} \mathrm{Hg} ; 35 \mathrm{~mm} \mathrm{Hg}<\mathrm{PCO}_{2}<45 \mathrm{~mm} \mathrm{Hg} ; 7.25$ $<\mathrm{pH}<7.45)$. For all animals, the heart rate and arterial blood pressure remained uneventful during experimentation.

The birthwt of lambs increased progressively from $1.40 \mathrm{~kg}$ at 108 days postconceptional age to $5.50 \mathrm{~kg}$ at 154 days postconceptional age (term: 147 days). The tracheal diameter increased from $4.0 \mathrm{~mm}$ at 108 days to $14.0 \mathrm{~mm}$ at 154 days. The vol of the bypassed segments also increased with developmental age.

Typical pressure-vol relationships for the newborn and preterm trachea are depicted in Figure 3. The volume on the ordinate is

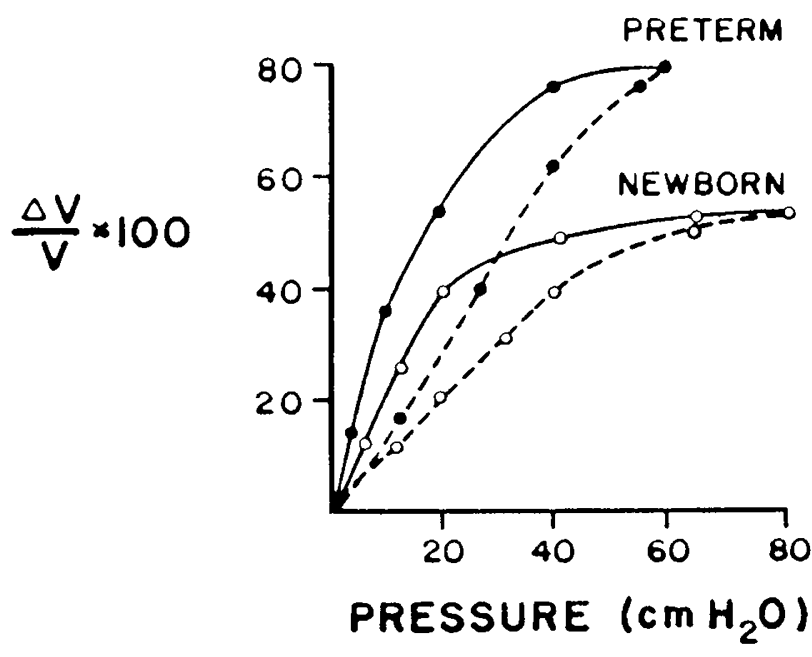

Fig. 3. Typical pressure-vol loops of the trachea in the preterm (-) and newborn $(\mathrm{O})$. Dotted lines represent pressure changes away from 0 transmural pressure; solid lines indicate pressure changes back toward 0 transmural pressure.

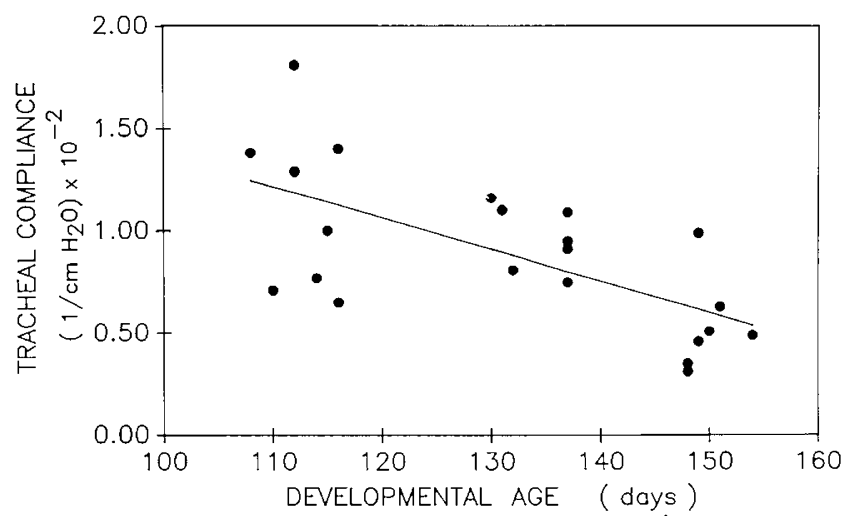

Fig. 4. Developmental changes in specific tracheal compliance.

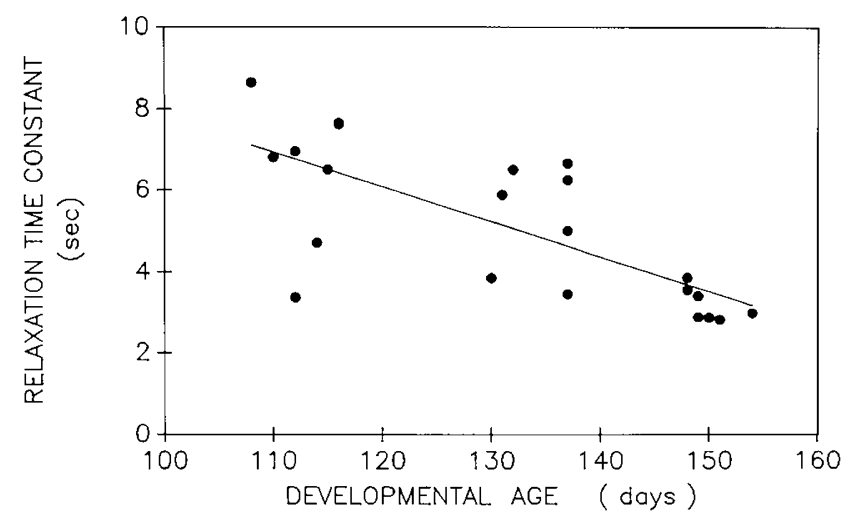

Fig. 5. Age-related alterations in the smooth muscle relaxation time constant.

expressed as a percentage of the relative change in the resting vol of the bypassed segment. The pressure-vol relationships exhibit a characteristic sigmoid shape with hysteresis during inflation and deflation. The slope of the deflation limb is steeper in the preterm airway as compared to the newborn. Furthermore, the plateau portion of the curves represented the maximum achievable percentage change in vol distensibility. This maximum vol change was inversely related to developmental age. Although in several cases the inflation and deflation limbs did not return to resting vol of the segment at a 0 transmural pressure, this was not a typical finding and therefore is not illustrated in Figure 3. $\mathrm{C}_{\mathrm{s}}$ normalized for segment vol was plotted (Fig. 4) and correlated with developmental age $\left(\mathrm{C}_{\mathrm{s}}=-0.015 \mathrm{DA}+2.92 ; r=0.65 ; p<\right.$ 0.001 ; where $\mathrm{DA}=$ developmental age). Airway compliance was found to decrease by $53 \%$ with increasing developmental age between 108 and 154 days postconceptional age.

As shown in Figure 5 , the smooth muscle relaxation time constant, $\left(\tau_{\mathrm{R}}\right)$, correlated significantly $(r=0.73 ; p<0.001)$ to developmental age $\left(\tau_{R}=-0.086 \mathrm{DA}+16.35\right)$. Values for $\tau_{R}$ obtained before 115 days developmental age exhibited a wide variance.

\section{DISCUSSION}

In this study we have described in vivo elastic and viscoelastic properties of the trachea through the early stages of gestation $(0.73$ term $)$ in the preterm lamb to the newborn period. Both tracheal compliance and relaxation time constant were inversely correlated to developmental age. Tracheal compliance values determined in vivo were found to be lower than those previously obtained in in vitro for both preterm and term lambs. These observations suggest underlying roles of smooth muscle tones and connective tissue in determining tracheal mechanics. 
Cardiopulmonary stability of the preterm lambs with respect to oxygenation, $\mathrm{CO}_{2}$ elimination, and acid-base and hemodynamic status was achieved using liquid ventilation support. In addition, the tracheal segments were maintained intact to preserve vascular and neural integrity. Thus, specific care was taken to minimize systemic variations that have been shown to affect smooth muscle tone and could potentially alter elastic and viscoelastic properties of the airways during the study period (14, 17).

Tracheal elastic properties. The elastic properties of the airways have been extensively evaluated as a function of developmental age in both in vitro animal studies $(8,9)$ and human postmortem studies $(7,10)$. These studies document the inverse relationship between tracheal compliance and developmental age. In the present study, the $53 \%$ decrease in tracheal compliance in lambs is similar to that seen in the rabbit pup studied over a similar developmental range of 0.67 gestation to term (8). Age-related differences in airway compliance may explain in part many of the clinical observations associated with the premature infant such as high resistance to airflow, flow limitation at low efforts, and reduced expiratory reserve $(12,13,18)$. In addition, the compliant airways of premature infants appear highly susceptible to alterations in their dimensions $(5,12)$ and mechanical properties (12) when chronically subjected to positive pressure ventilation. Morphometric changes characteristic of acquired tracheomegaly and bronchopulmonary dysplasia may represent attempts by the immature airway to minimize wall stress during ventilation, similar to changes exhibited by the vascular wall consequent to hypertension.

Despite the similarity of age-related correlations determined in vivo compared to the in vitro condition, the absolute values of specific tracheal compliance was markedly higher in both the 134-day gestation lamb $\left(2.7 \times 10^{-2} \mathrm{~cm} \mathrm{H}_{2} \mathrm{O}^{-1}\right)$ and term lamb $\left(2.1 \times 10^{-2} \mathrm{~cm} \mathrm{H}_{2} \mathrm{O}^{-1}\right)$ when determined in vitro $(11,19)$. These differences between in vivo and in vitro studies suggest that neural-humoral and surrounding connective tissues factors may affect the elastic properties of the developing airway. In previous studies, we described the influence of tracheal smooth muscle tone in modulating tracheal mechanics in both the preterm (13) and term $(16,20)$ lamb. Increased smooth muscle tone reduces tracheal compliance by stiffening the posterior wall and limiting the extent of posterior wall evagination associated with a given transmural pressure. The in vivo state may retain mechanisms (such as neural or humoral stimulation) that produce a greater degree of smooth muscle tone that exists in vitro, thus explaining observed differences in tracheal compliance.

In addition, surrounding connective tissue may further serve to limit tracheal distensibility and contribute to lower compliance values determined in vivo.

In a similar manner, differences in tracheal smooth muscle force generating ability may underlie developmental differences in airway compliance. Panitch et al. (21) have demonstrated agerelated differences in both passive and active tension generation ability of lamb trachealis in vitro. However, interplay between in vivo influences and inherent muscle properties warrants the appropriate in vivo studies throughout a developmental range before any definitive conclusions may be drawn.

Tracheal viscoelastic properties. The observed correlation of the relaxation time constant $\tau_{R}$ with increasing immaturity is also suggestive of age-related differences in trachealis tone in vivo. In the present study, $\tau_{\mathrm{R}}$ increased from a value of $2.98 \mathrm{~s}$ in a term lamb (154 days postconceptional age) to $8.64 \mathrm{~s}$ at 108 days. Previous studies have demonstrated the influence of increased trachealis tone on time-dependent pressure-vol changes in both the adult canine (22) and newborn lamb (16). Both studies indicated a greater rate of relaxation (after vol injection) in groups that had been stimulated to increase smooth muscle tone. Age-related differences in $\tau_{\mathrm{R}}$ may therefore be determined in part by differences in tone present in the in vivo state.

In conclusion, the use of liquid ventilation techniques has allowed us to examine age-related differences in tracheal elastic and viscoelastic properties in vivo for the first time. Both tracheal compliance and the stress relaxation time constant were found to decrease with maturity, and values were markedly lower than those observed in vitro. These differences may be a result of underlying difference in the force-generating ability of tracheal smooth muscle, which may vary as a function of developmental age and experimental condition.

Acknowledgments. The authors are grateful to Mark Alsberge and Robert Roache for their technical assistance. We acknowledge the support of Merchantile Development Inc., for supplying the fluorocarbon liquid (Rimar 101) for this study.

\section{REFERENCES}

1. Northway WH, Rosan RC, Porter DY 1967 Pulmonary disease following respirator therapy of hyaline membrane disease: bronchopulmonary dysplasia. N Engl J Med 276:357-368

2. O'Brodovich HM, Mellins RB 1985 Bronchopulmonary dysplasia (state of the art). Am Rev Respir Dis 132:684-709

3. Bhutani VK, Ritchie WG, Shaffer TH 1986 Acquired tracheomegaly in very preterm neonates. Am J Dis Child 140:449-452

4. Palmer J, Schidlow D, Wolfson B, Capitiano M, Huang N 1979 Tracheomegaly: a finding in two children who survived prolonged intubation and mechanical ventilation for hyaline membrane disease. Pediatr Res 13:1282 (abstr)

5. Bhutani WK, Rubenstein SD, Shaffer TH 1981 Pressure-induced deformation in immature airways. Pediatr Res 15:829-832

6. Snyder SM, Shaffer TH, Bhutani VK 1984 Tracheal volume deformation in a developmental rabbit model. Biol Neonate 46:192-197

7. Croteau JR, Cook CD 1961 Volume-pressure and length-tension measurements in human tracheal and bronchial segments. J Appl Physiol 16:170172

8. Bhutani VK, Rubenstein SD, Shaffer TH 1981 Pressure-volume relationships of trachea in fetal, neonatal, and adult rabbits. Respir Physiol 43.221-231

9. Mortola JP 1987 Dynamics of breathing in newborn mammals. Physiol Rev 67:187-243

10. Burnard ED, Grattan-Smith P, Picton-Marlow CG, Grauaug A 1965 Pulmonary insufficiency in prematurity. Aust Paediatr J 1:12-38

11. Koslo RJ, Wolfson MR, Shaffer TH 1983 Tracheal mechanics: a comparative study. Fed Proc 42:616 (abstr)

12. Penn RB, Wolfson MR, Shaffer TH 1988 Effect of ventilation on mechanical properties and pressure-flow relationships of immature airways. Pediatr Res 23:519-524

13. Penn RB, Wolfson MR, Shaffer TH 1988 Effect of tracheal smooth muscle tone on the collapsibility of extremely immature airways. J Appl Physio 65(2):863-869

14. Stephens NL, Meyers JL, Cherniak RM 1968 Oxygen, carbon dioxide, $\mathrm{H}^{+}$ion and bronchial length-tension relationships. J Appl Physiol 25:376-383

15. Shaffer TH, Tran NN, Bhutani VK, Sivieri EM 1983 Cardiopulmonary function in very preterm lambs during liquid ventilation. Pediatr Res 17:680684

16. Koslo RJ, Bhutani VK, Shaffer TH 1986 The role of tracheal smooth muscle contraction on neonatal tracheal mechanics. Pediatr Res 20:1216-1220

17. Stephens NL, Hoppin FG Jr 1986 Mechanical properties of airway smooth muscle. In: Macklem PT, Mead J (eds) Handbook of Physiology, Vol 3. American Physiological Society, Washington, D.C., pp 263-276

18. Tepper RS, Morgan WJ, Cota K, Taussig LM 1986 Expiratory flow limitation in infants with bronchopulmonary dysplasia. J Pediatr 109:1040-1046

19. Bhutani VK, Shaffer TH 1983 Effect of liquid ventilation on preterm tracheal mechanics. Biol Neonate 44:257-263

20. Bhutani VK, Koslo RJ, Shaffer TH 1986 The effect of tracheal smooth muscle tone on neonatal airway collapsibility. Pediatr Res 20:492-495

21. Panitch H, Allen J, Ryan J, Wolfson MR, Shaffer TH 1987 Developmental aspects of tracheal smooth muscle force generation and length-tension relationships. Fed Proc 46(3):661 (abstr)

22. Coburn RF, Palombni B 1972 Time-dependent pressure-volume relationships of the in vivo canine trachea. Respir Physiol 16:282-289 